\section{Бекмурзиева X.M.}

аспирант, ФГБОУ ВО «Российский экономический университет имени Г.В. Плеханова», г. Москва e-mail: xadi_bek@mail.ru

\section{Bekmurzieva Kh.M.}

Postgraduate student, Plekhanov Russian University of Economics, Moscow

e-mail: xadi_bek@mail.ru

\section{Мотивация деятельности государственных гражданских служащих как средство повышения эффективности государственной гражданской службы}

\begin{abstract}
Аннотация
Статья посвящена актуальным проблемам мотивации работников государственных органов в Российской Федерации. Человеческий фрактор является основным элементом производительности труда и увеличения эффрективности деятельности организации. Важнейшим направлением повышения эффективности государственной гражданской службы является разработка комплекса по совершенствованию работы государственных гражданских служащих. Государственные гражданские служащие - фундамент государственного аппарата. В современных условиях эфффективное функционирование государственного аппарата невозможно без активного участия государственных служащих в достижении национальных целей и задач. Результативность деятельности государственных служащих во многом зависит от их заинтересованности в исполнении служебных обязанностей на высоком уровне. Одним из методов повышения эфффективности государственной гражданской службы может выступить грамотно разработанная система мотивации. В целях недопущения рассогласования в понимании системы мотивации автором ссрормирован основной понятийный аппарат по теме. Установлено, что основным средством управления мотивацией государственных служащих в России в настоящее время являются денежные выплаты. Автором приведены составляющие денежного содержания государственного гражданского служащего. Обоснована необходимость проведения ресормы заработной платы государственных служащих. По результатам проведенного автором исследования сформулированы возможные направления совершенствования трудовой деятельности государственных гражданских служащих. Выработаны предложения по совершенствованию государственной службы в Российской Федерации, в первую очередь предлагается внедрение трудового договора по принципу «эфффективный контракт». Установлено, что в отношении каждого государственного служащего при заключении эффрективного контракта должны быть детализированы его функционал, показатели и критерии оценки эффективности деятельности, установлен размер вознаграждения, размер поощрения за достижение коллективных результатов труда. Предложены основные критерии оценки деятельности государственных гражданских служащих.
\end{abstract}

Ключевые слова:

государственная служба, государственный аппарат, мотивация, повышение эффективности, эффрективный контракт, критерии оценки деятельности государственных служащих.

\section{The motivation of activity of civil servants as a means to improve the efficiency of the public civil service}

\begin{abstract}
The article has devoted to topical issues of motivation of employees of state bodies in the Russian Federation. The human factor is the main element of labor productivity and increase the efficiency of the organization. The development of a complex for improving the work of civil servants is one of the most important direction in increasing the efficiency of the public civil service. Civil servants -are the foundation of the state apparatus. In modern conditions, the effective functioning of the state apparatus is impossible without the active participation of civil servants in achieving national goals and objectives. The effectiveness of the activities of civil servants depends largely on their interest in the performance of official duties at a high level. One method of increasing the efficiency of the civil service can be a well-designed system of motivation. In order to avoid mismatch in understanding the motivation system, the author has formed the basic conceptual apparatus on the topic. It has established that the main means of managing the motivation of civil servants in Russia at present is cash payments. The author presents the components of the salary of a civil servant. The necessity of reform of public servants has substantiated. According to the results of the study conducted by the author, possible directions for improving the work activities of civil servants have formulated. A set of measures to improve the civil service in the Russian Federation has proposed, primarily, the introduction of an employment contract according to the «effective contract» principle is proposing. It has established that in relation to each public servant, when concluding an effective contract, his labor function, indicators and criteria for evaluating the effectiveness of activities should be specified, the amount of remuneration, the amount of incentives for achieving collective results of labor should be established. The main criteria for evaluating the activities of civil servants has proposed.
\end{abstract}

Keywords:

public service, state apparatus, motivation, increase efficiency, effective contract, criteria for evaluating the activities of civil servants.

(C) The Author(s), 2018 This is an open access article under the CC BY 4.0 license (http://creativecommons.org/ licenses/by/4.0/) 
В условиях нарастающего внешнего давления на Российскую Федерацию (далее - РФ), и как следствие, осложнения политической и экономической ситуации в стране, усиления общественных противоречий существует необходимость повышения эффективности государственного управления в целом и государственного аппарата в частности. В связи с этим необходимость повышения эффективности труда государственных гражданских служащих (далее - госслужащие, гражданские служащие) приобретает особую значимость.

Производительность труда является одним из факторов экономического роста и благосостояния страны. Человеческий фактор, в свою очередь, выступает ключевым элементом роста производительности труда, повышения эффективности и конкурентоспособности любой организации, в данном случае государственной структуры.

Необходимым условием в построении эффективно функционирующего российского государства является становление государственной службы (далее - госслужба), которая будет призвана служить гражданам и обществу в целом. Произошедшие за последние года изменения на территории РФ обозначили необходимость и важность повышения эффективности госслужбы.

Госслужащие - фундамент государственного аппарата. Имея соответствующий уровень квалификации, конкретные желания, исходя из определенной системы ценностей, и следуя установленным нормам и правилам, госслужащий способен выполнять свою работу на высоком профессиональном уровне. Именно стремление и способность гражданского служащего высокопрофессионально исполнять должностные обязанности - один из ключевых факторов эффективной деятельности государственного органа.

Отечественная и зарубежная практика однозначно свидетельствует: если в организациях не ведется планомерная работа в области управления трудовой мотивацией, то рассчитывать на эффективную деятельность в текущем и долгосрочном периодах бессмысленно. В любой организации, коммерческой или бюджетной, руководителям всех уровней управления необходимо осознавать значимость влияния мотивации на результативность трудовой деятельности своих сотрудников [9].

Одним из методов повышения эффективности госслужбы может выступить грамотно разработанная система мотивации.

«Мотивация - это внутренний процесс сознательного и самостоятельного выбора самим человеком той или иной модели поведения, определяемой комплексным воздействием внешних (стимулы) и внутренних (мотивы) факторов для удовлетворения своих потребностей» [4, с. 12].

В настоящее время существуют проблемы в системе мотивации госслужащих, к которым относят снижение общего уровня мотивации, преобладание материальных потребностей у чиновников, неэффективную систему их материального стимулирования, недостаточную проработанность социальнопсихологических механизмов стимулирования [3].

В разные годы рядом авторов (К. Х. Абдурахманов, И. А. Баткаева, Л. В. Вагина, Г. П. Гагаринская, В. А. Дятлов, А. Ф. Зубкова, Н. И. Захаров, Т. Г. Калачева, Е. Д. Катульский, Ю. П. Кокин, В. В. Куликов, А. А. Литвинюк, Б. В. Лытов, В. А. Мальцев, В. И. Матирко, О. И. Меньшикова, Ю. В. Синягин, Р. А. Яковлев и др.) были проведены исследования в части профессиональной деятельности госслужащих. Обобщив результаты исследований, можно сказать, что в целом мотивация является важнейшим процессом в современном управлении человеческими ресурсами как в частном, так и в государственном секторе. В кадровой работе государственных структур процесс мотивации включает в себя комплекс стимулирующих мероприятий, разработанных на основе мотивов, интересов и потребностей госслужащего, которые побуждают выполнять свои обязанности как можно эффективнее и результативнее.

Несмотря на многообразие исследований факторов управления мотивацией труда в госслужбе, очевидно, что существует необходимость переоценки нынешних методов мотивации и совершенствования системы в целом.

«Сегодня прогресс в социально-экономическом развитии организации напрямую зависит от того, насколько грамотно ее руководитель учитывает индивидуально-типологические особенности личности своих сотрудников при выстраивании системы мотивации» [4, с. 11].

Руководству важно иметь четкое понимание того, что движет подчиненным и побуждает его к определенным действиям, к чему он стремится. Благодаря четкому пониманию факторов мотивации того или иного госслужащего можно выработать систему управления подчиненным таким образом, что он сам будет стремиться эффективно и результативно выполнять поставленные перед ним задачи.

На сегодняшний день существует некое рассогласование в понимании мотивации в принципе. Зачастую эффективность применяемых систем мотивации снижается за счет смешения понятий «мотивация», «мотивирование», «стимулирование». В связи с этим для разработки обоснованных предложений в первую 
очередь необходимо формирование понятийного аппарата.

Мотивирование и стимулирование, являющиеся ключевыми понятиями в теории мотивации, выступают средством влияния на мотивацию человека, но имеют содержательные отличия.

Мотивирование - воздействие непосредственно на индивида с целью изменения его ценностной ориентации и потребностей, формирования определенных мотивов и развитие на этой основе трудового потенциала.

Трудовой потенциал - часть потенциала личности, которая формируется на основе имеющихся способностей, уровня образования, воспитания и жизненного опыта. Трудовой потенциал совершенствуется в течение профессиональной жизнедеятельности личности и определяет эффективность труда, оказывающую влияние на общую производительность организации в целом.

Стимулирование является инструментом управления мотивацией человека посредством внешнего побуждения к активности через различные блага (стимулы), способные удовлетворить потребности человека [4]. Стимулирование трудовой деятельности в организациях осуществляется с помощью системы материального и морального воздействия. Таким образом, происходит актуализация и усиление мотивов, не меняя саму структуру мотивации.

Процессы мотивирования и стимулирования также тесно связаны с такими понятиями, как мотив и стимул.

Мотив зависит от индивидуальных особенностей личности и носит персональный характер. Именно мотив побуждает индивида к некой совокупности действий и определяет, как именно они будут осуществлены.

Стимул, в отличие от мотива, имеет воздействие непосредственно на поведение индивида. Реакция человека на стимулы индивидуальна и не всегда сознательна. В виде стимулов подразумеваются материальные и духовные блага.

Мотив относится к внутренней среде человека, в то время как стимул - к внешней.

Инструменты мотивации, выступающие как средство воздействия на подчиненных, при грамотном использовании способствуют достижению высоких результатов и показателей труда. Очевидно, что эффективная система мотивации будет способствовать повышению эффективности деятельности госслужащих.

Изучение особенностей мотивации деятельности госслужащих проводится достаточно длительное время различными исследователями. Так, в 2005 г.
Фондом «Институт экономики города» и Институтом сравнительных исследований трудовых отношений было проведено исследование, которое показало, что основными мотивами, привлекающими к госслужбе, являются: «факторы социальных гарантий, защищенности $(75,7 \%)$, регулярность оплаты труда (56 \%), стабильность занятости (47 \%)» [5].

В 2015-2016 гг. Ю. В. Синягин в рамках курсов повышения квалификации ВШГУ РАНХиГС при Президенте РФ проанализировал мотивы предпочтительного выбора госслужбы как сферы профессиональной деятельности [8]. В рамках данного исследования «было опрошено 56 руководителей государственной гражданской службы разного уровня в возрасте от 27 до 62 лет. Результаты исследования показали следующее: выбор профессии госслужащего обусловлен обеспечением стабильности и независимости такой профессиональной позиции, ее защищенностью от разных реформ (это отметило почти $43 \%$ опрошенных)» [8, с. 89].

«Сами опрошенные госслужащие важными аспектами профессиональной деятельности в системе госслужбы называют «стабильность места работы» (79 \%) и «достойную заработную плату» (55\%). Интересно, что «самореализацию» (отметило 49 \%) и «продвижение по службе» $(44 \%)$ опрошенные считают менее важными факторами в их жизни» [8, с. 87].

Результаты анализа существующей практики мотивации государственных гражданских служащих РФ показывают, что в качестве решающего фактора мотивации выступает материальное стимулирование гражданских служащих.

Для граждан, начинающих свою профессиональную деятельность в органах государственной власти, госслужба, как вид профессиональной деятельности часто становится промежуточным этапом. Молодые специалисты рассматривают госслужбу как некую первую, но очень полезную ступень в карьере, которая позволяет получить полезный опыт в государственных учреждениях, дает возможность обучиться работе, жестко регламентированной как по качеству, так и по срокам, позволяет улучшить свои навыки, повысить квалификацию, а также завести полезные деловые знакомства. Получив достаточный опыт работы на госслужбе, молодые специалисты без особых затруднений находят высокооплачиваемую работу в коммерческих структурах, где их предыдущий опыт работы в органах государственной власти оценивается как знак некого качества.

На сегодняшний день основным методом управления мотивацией в государственном секторе являются денежные выплаты, в то же время, согласно статье 50 Федерального закона № 79-Ф3 
«О государственной службе Российской Федерации», денежные выплаты выступают основным средством стимулирования профессиональной деятельности госслужащего [1].

Вопреки имеющимся исследованиям в области управления мотивацией сотрудников частного сектора, исследований в области государственного управления недостаточно. Основная часть имеющихся знаний о мотивации в государственном секторе - это на самом деле теории, которые исходят из исследований трудовой мотивации в частном секторе. Таким образом, разработка мероприятий по повышению эффективности деятельности госслужащих является актуальным направлением совершенствования госслужбы в целом, а исследование мотивации деятельности госслужащих приобретает особую значимость.

Для того, чтобы государственные служащие были удовлетворены на своем рабочем месте, их вознаграждение с помощью оклада или неосновных методов в соответствии с полученными результатами абсолютно необходимо.

Существующая система мотивации гражданских служащих РФ имеет ряд проблем. В Федеральном законе «О государственной гражданской службе Российской Федерации» отсутствует понятие мотивации государственных служащих. В соответствии со статьей 50 Федерального закона от № 79-Ф3 «О государственной гражданской службе Российской Федерации» денежное содержание гражданского служащего состоит из двух частей: основной и дополнительной [1].

«Денежное содержание - это форма оплаты труда гражданского служащего, являющаяся основным средством его материального обеспечения и стимулирования профессиональной служебной деятельности по замещаемой должности гражданской службы» [1].

«Денежное содержание состоит из двух частей: основной и дополнительной» [1].

«Основная часть денежного содержания состоит из должностного оклада и оклада за классный чин» [1].

«Должностной оклад - месячный оклад гражданского служащего в соответствии с замещаемой им должностью гражданской службы» [1].

«Оклад за классный чин - месячный оклад гражданского служащего в соответствии с присвоенным ему классным чином гражданской службы» [1].

Должностной оклад и оклад за классный чин в совокупности составляют оклад месячного денежного содержания гражданского служащего (оклад денежного содержания).

Размеры должностных окладов и окладов за классный чин федеральных госслужащих устанавливаются Указом Президента РФ.
Дополнительная часть, согласно пункту 5 статьи 50 Федерального закона № 79-Ф3, состоит из следующих выплат:

- ежемесячная надбавка к должностному окладу за выслугу лет на гражданской службе;

- ежемесячная надбавка к должностному окладу за особые условия гражданской службы;

- ежемесячная процентная надбавка к должностному окладу за работу со сведениями, составляющими государственную тайну;

- премии за выполнение особо важных и сложных заданий;

- ежемесячное денежное поощрение;

- единовременная выплата при предоставлении ежегодного оплачиваемого отпуска;

- материальная помощь [1].

Суть дополнительной части заключается в том, чтобы увеличить месячный оклад госслужащего. В то же время дополнительную часть заработной платы можно отнести к постоянной или к условнопеременной части.

Премии за выполнение особо важных и сложных заданий, в свою очередь, не имеют жесткой привязки к конкретным профессиональным достижениям и результатам, их размер зависит от усмотрения руководства структурного подразделения и, более того, они ограничены в пределах средств фонда оплаты труда, предусмотренных ведомством на соответствующий финансовый год.

Денежное содержание госслужащих в РФ, в соответствии с законодательством, является основным мотивом профессиональной служебной деятельности. Однако уровень оплаты труда трудоемкой и масштабной деятельности госслужащих, по сравнению с коммерческими структурами, относительно невысокий, а имеющиеся социальные гарантии и поощрения не компенсируют данную разницу в полной мере. Очевидно, что эффективность используемых методов мотивации требует изменений. Этим определяется необходимость изменения существующей системы мотивации и стимулирования труда госслужащих.

На целесообразность пересмотра размеров окладов госслужащих в настоящее время указывает и экономическая ситуация в стране - уровень доходов госслужащих отстает от темпов инфляции.

Исходя из сказанного выше, реформу заработной платы госслужащих необходимо провести по двум основным направлениям: во-первых, следует реализовать на практике четкие критерии, чтобы увязывать их денежное содержание с результатами труда, во-вторых, необходимо создать совершенную систему систематической индексации основного 
оклада госслужащих, которая была бы законодательно закреплена.

Таким образом, одним из мероприятий по совершенствованию системы мотивации деятельности госслужащих может выступить законодательно зафиксированный механизм систематической индексации базового оклада.

В целях стимулирования госслужащего быть нацеленным в большей степени на достижение высоких показателей результативности в служебной деятельности целесообразно заключение трудового договора по принципу «эффективного контракта».

Согласно распоряжению Правительства РФ «Эффективный контракт - трудовой договор с работником, в котором конкретизированы его должностные обязанности, условия оплаты труда, показатели и критерии оценки эффективности деятельности для назначения стимулирующих выплат в зависимости от результатов труда и качества оказываемых государственных (муниципальных) услуг, а также меры социальной поддержки» [2]. Исходя из определения, основными направлениями проектирования эффективной системы мотивации трудовой деятельности госслужащих выступают: соблюдение конкретизированных должностных обязанностей; показатели и критерии результатов деятельности; качество выполняемых государственных услуг (функций).

К примеру, премии за выполнение особо важных и сложных заданий, являющиеся стимулирующими выплатами, целесообразно связать с результатами служебной деятельности госслужащих, связав их с конкретными критериями по оценке.

В связи с этим возникает необходимость приведения в надлежащее состояние системы критериев оценки эффективности деятельности госслужащих, применяемых для целей эффективного контракта. Основными критериями при этом целесообразно определить:

- перевыполнение заданий и поручений в соответствии с должностными обязанностями гражданского служащего, выполнение заданий повышенной сложности;

- образцовое соблюдение служебной дисциплины, интенсивность прохождения гражданской службы за пределами нормальной продолжительности служебного времени;

- высокое качество исполнения гражданским служащим должностных обязанностей, положительные отзывы руководителя, наличие благодарностей и грамот;

- отсутствие периодов временной нетрудоспособности гражданского служащего, неоплачиваемых отпусков.
Трудовой договор по принципу «эффективного контракта» должен быть изложен в понятной форме, исключающей двойное толкование, конкретизируя должностные обязанности госслужащего и условия оплаты труда, показатели и критерии оценки эффективности его деятельности для назначения стимулирующих выплат в зависимости от результатов труда, качества выполняемых функций.

Резюмируя выше написанное, очевидно, что на данный момент следует заниматься не только повышением оплаты труда, но и совершенствованием карьерных механизмов, а также повышением социальных гарантий и статуса самой госслужбы. В том числе следует применять социально-психологические приемы к повышению эффективности мотивации работников госслужбы.

Вместе с этим, следует учитывать и эффективную мотивацию госслужащих, которая будет влиять на повышение производительности труда работников, а также включать совокупность взаимосвязанных элементов (создание комфортных социальнопсихологических условий, модернизация кадровых технологий и т. д.) [6].

С учетом специфики деятельности государственных органов власти, стоящими перед ними задачами, мотивацией для госслужащих может стать престиж статуса государственных гражданских служащих, достойная оплата труда, прозрачная система карьерного роста с определенными критериями для этого, социальные гарантии и льготы. Оплата труда в деятельности госслужащего является основным материальным стимулом, поэтому уровень заработной платы должен соотноситься с уровнем в коммерческом секторе на аналогичной позиции.

Таким образом, важнейшим направлением реформирования и повышения эффективности государственной гражданской службы Российской Федерации на современном этапе является создание гибкой системы стимулирования ее служащих. Возможность формирования нового подхода как к управлению государственным аппаратом, так и к путям решения задач, стоящих перед государственными органами, является основной задачей модернизации государственных структур. 


\section{Библиографический список}

1. Федеральный закон «О государственной гражданской службе Российской Федерации» от 27.07.2004 г. № 79Ф3 (ред. от 30.10.2018) [Электронный ресурс]. - Режим доступа: Справочная правовая система «КонсультантПлюс» http://www.consultant.ru/cons/ (дата обращения: 08.11.2018).

2. Распоряжение Правительства РФ «Об утверждении Программы поэтапного совершенствования системы оплаты труда в государственных (муниципальных) учреждениях на 2012-2018 годы» от 26.11.2012 г. № 2190-р (ред. от 14.09.2015) [Электронный ресурс]. Режим доступа: Справочная правовая система «КонсультантПлюс» http://www.consultant.ru/cons/ (дата обращения: 08.11.2018).

3. Бахрах, Д. Н. Государственная служба в Российской Федерации / Д. Н. Бахрах. - М.: Издательство Государственной юридической академии, 2014. - С. 502505.

4. Литвинюк, А. А. Мотивация и стимулирование трудовой деятельности. Теория и практика: учебное пособие / А. А. Литвинюк. - М.: Юрайт, 2014. - 400 с.

5. Отчет по результатам обследования государственных гражданских и муниципальных служащих «Обследование оплаты труда в регионах и опрос государственных гражданских служащих» [Электронный ресурс] // Фонд «Институт экономики города», Институт сравнительных исследований трудовых отношений. - Режим доступа: http://www.urbaneconomics.ru/node/8675 (дата обращения: 10.11.2018).

6. Рыжкова, А.О. Анализ системы мотивации государственных гражданских служащих в современной России [Электронный ресурс] // Молодежный научный форум: электр. сб. ст. по мат. Х междунар. студ. науч.практ. конф. № 9 (10). - Режим доступа: https:// nauchforum.ru/archive/MNF_interdisciplinarity/9(10).pdf (дата обращения: 12.11.2018).

7. Синягин, Ю. В. Мотивация и демотивация в государственной службе: результаты опроса руководителей [Электронный ресурс] // Современное общество и власть. - Режим доступа: http://gmanagement.ru/ index.php/ru/arxiv/2-2017r/566-sinyagin-122017 (дата обращения: 10.11.2018).

8. Синягин, Ю. В. Оценка личности: ресурсный и компетентностный подходы // Проблемы педагогики и психологии. Научное периодическое издание межвузовского консорциума, выпуск 2. - Армянский государственный педагогический университет имени Хачатура Абовяна, 2014. - С. 85-93.

9. Формирование эффективной модели государственного управления в Российской Федерации - теоретические и прикладные аспекты: монография / Л. А. Жигун, Р. А. Абрамов, Р. Т. Мухаев, М. С. Соколов. - М.: «ИД Третьяков», 2016. - 234 с.

\section{References}

1. Federal'nyi zakon «O gosudarstvennoi grazhdanskoi sluzhbe Rossiiskoi Federatsii» ot 27.07.2004 g. № 79-FZ (red. ot 30.10.2018) [Federal Law «On the State Civil Service of the Russian Federation» dated July 27, 2004 № 79-FZ]. Available at: «Spravochnaya pravovaya sistema Konsul'tantPlyus» http://www.consultant.ru/cons/ (accessed 08.11.2018).

2. Rasporyazhenie Pravitel'stva RF ot 26.11.2012 g. № 2190-r (red. ot 14.09.2015) «Ob utverzhdenii Programmy poetapnogo sovershenstvovaniya sistemy oplaty truda v gosudarstvennykh (munitsipal'nykh) uchrezhdeniyakh na 2012-2018 gody» [Order of the Government of the Russian Federation "On Approval of the Program for the phased improvement of the wage system in state (municipal) institutions for 2012-2018»]. Available at: «Spravochnaya pravovaya sistema Konsul'tantPlyus» http://www.consultant.ru/cons/ (accessed 08.11.2018).

3. Bakhrakh D. N. Gosudarstvennaya sluzhba v Rossiiskoi Federatsii [Public service in the Russian Federation]. M: Izdatel'stvo Gosudarstvennoi yuridicheskoi akademii, 2014, pp. 502-505.

4. Litvinyuk A. A. Motivatsiya i stimulirovanie trudovoi deyatel'nosti. Teoriya i praktika: uchebnoe posobie [Motivation and stimulation of labour activity. Theory and practice: textbook]. M.: Yurait, 2014, 400 p.

5. Otchet po rezul'tatam obsledovaniya gosudarstvennykh grazhdanskikh i munitsipal'nykh sluzhashchikh «Obsledovanie oplaty truda v regionakh i opros gosudarstvennykh grazhdanskikh sluzhashchikh». [Report on the results of the survey of civil and municipal servants "Survey of wages in the regions and a survey of civil servants»]. Fond «Institut ekonomiki goroda», Institut sravnitel'nykh issledovanii trudovykh otnoshenii. Available at: http://www. urbaneconomics.ru/node/8675 (accessed 10.11.2018).

6. Ryzhkova A. O. Analiz sistemy motivatsii gosudarstvennykh grazhdanskikh sluzhashchikh v sovremennoi Rossii [Analysis of the system of motivation of civil servants in modern Russia]. Molodezhnyi nauchnyi forum: elektr. sb. st. po mat. X mezhdunar. stud. nauch.-prakt. konf. № 9 (10). Available at: https://nauchforum.ru/archive/MNF_interdisciplinarity/9(10).pdf (accessed 12.11.2018).

7. Sinyagin Yu. V. Motivatsiya i demotivatsiya v gosudarstvennoi sluzhbe: rezul'taty oprosa rukovoditelei [Motivation and demotivation in the public service: the results of a survey of managers]. Available at: http://gmanagement.ru/index. php/ru/arxiv/2-2017r/566-sinyagin-122017 (accessed 10.11.2018).

8. Sinyagin Yu. V. Otsenka lichnosti: resursnyi i kompetentnostnyi podkhody [Personality assessment: resource and competence approaches]. Problemy pedagogiki i psikhologii. [Problems of pedagogy and psychology]. Nauchnoe periodicheskoe izdanie mezhvuzovskogo konsortsiuma, vypusk 2. Armyanskii gosudarstvennyi pedagogicheskii universitet imeni Khachatura Abovyana, 2014, pp. 85-93.

9. Zhigun L. A., Abramov R. A., Mukhaev R. T., Sokolov M. S. Formirovanie effektivnoi modeli gosudarstvennogo upravleniya v Rossiiskoi Federatsii - teoreticheskie i prikladnye aspekty: monografiya [Formation of an effective model of government in the Russian Federation - theoretical and applied aspects: Monograph]. M.: «ID Tret'yakov», 2016. 234 p. 